\title{
Performance of Network-Based RTK GPS in Low- Latitude Region: A Case Study in Thailand
}

\author{
Teeratat Charoenkalunyuta $^{1, \mathrm{a}}$, Chalermchon Satirapod ${ }^{1, \mathrm{~b}}$, Hung-Kyu Lee ${ }^{2, \mathrm{c}}$, \\ and Yoon-Soo Choi ${ }^{3, \mathrm{~d}}$ \\ 1 Department of Survey Engineering, Chulalongkorn University, Bangkok 10330, Thailand \\ 2 Department of Civil Engineering, Changwon National University, 9 Sarim-dong Changwon, Gyeongnam \\ 641-773, Republic of Korea \\ 3 Department of Geoinformatics, University of Seoul, 90 Jeonnong-dong, Dongdaemum-gu, Seoul, 130- \\ 743, Republic of Korea \\ E-mail: ateeratat.c@student.chula.ac.th, bChalermchon.s@chula.ac.th (Corresponding Author), \\ chkyulee@changwon.ac.kr, dchoiys@uos.ac.kr
}

\begin{abstract}
Thailand has established a Network-based Real Time Kinematic (NRTK) GPS system using the Virtual Reference Station (VRS) concept since 2008. Currently, the Thai NRTK consists of 11 reference stations located in the central part of Thailand with averaged reference station spacing at $60 \mathrm{~km}$. A previous test suggested some problems with the low rate of ambiguity-fixing and the large number of position jumps even when the ambiguity-fixed solutions could be obtained. In this paper, the position performance of NRTK is tested with a large number of GPS observations (31 consecutive days) and different reference receiver spacing, 10-20, 30-50, 50-60 and $60-80 \mathrm{~km}$, with the use of all available Continuous GPS (CGPS) stations in the central part of Thailand. Test results indicate that the NRTK positioning performance is degraded when the reference station spacing is increased. It is also found that the ionospheric bias is the main error source that affects the performance of NRTK in Thailand. Even with the $10-20 \mathrm{~km}$ reference station spacing, reliable ambiguity-fixed solutions could hardly be obtained during the period of high ionospheric variation. Thus, it is recommended that the reference station spacing should be kept less than $30 \mathrm{~km}$. In order to achieve the reliable NRTK solutions especially in low-latitude region like Thailand, the ionospheric bias should be properly handled.
\end{abstract}

Keywords: Network-based RTK GPS, VRS, low-latitude region, reference station spacing, ionospheric bias.

ENGINEERING JOURNAL Volume 16 Issue 5

Received 19 April 2012

Accepted 6 June 2012

Published 1 October 2012

Online at http://www.engj.org/

DOI:10.4186/ej.2012.16.5.95 


\section{Introduction}

Since Real-Time Kinematic (RTK) GPS technique was introduced in the mid 1990s, this technique has become a common tool for various applications which require high accuracy positioning results in real-time. It is generally known that the performance of traditional RTK GPS technique is limited by the distance between a reference and roving receiver. Accuracy and reliability of the results usually decrease when the baseline length increases. In order to maintain cm-level accuracy positioning result from the RTK GPS technique, the roving receiver is usually required to locate within approximately $10 \mathrm{~km}$ from the reference receiver. To overcome the baseline length limitation, the Network-based RTK (NRTK) concept has been proposed since the late 1990s. The NRTK technique uses several reference stations surrounding the roving receiver to improve the mitigation of the spatially correlated atmospheric and satellite orbit biases [1]. In the Asian region, several NRTK services have been established, for example, the Malaysian Real-Time Kinematic Network (MyRTKnet) was established with an average spacing of between 30 and $120 \mathrm{~km}$ [2], while the Singapore Integrated Multiple Reference Station Network (SIMRSN) [3], the Hong Kong GPS active network [4] and the Taiwan GPS network [5] were established with average spacings of $16.9 \mathrm{~km}$, $10 \mathrm{~km}$ and $34 \mathrm{~km}$ respectively. An average spacing tends to vary for each country due to variability of atmospheric biases.

In recent years, the Department of Lands (DOL) in Thailand has been establishing the Virtual Reference Station (VRS) - NRTK system mainly to support cadastral surveying applications. The DOL VRS network comprises of 11 reference stations located in the Central Plain region with spacing ranging from 27.8 to $125.6 \mathrm{~km}$, the average spacing is around $60 \mathrm{~km}$. The performance of the DOL VRS network was tested using a static mode for rover antennas [6]. The test results revealed that in general the horizontal positioning accuracy could be achieved within $4 \mathrm{~cm}$ when the ambiguity-fixed solutions were available. However, many large positioning jumps were observed in the local pre-midnight period even with the ambiguity-fixed solutions. It is also important to note that the ambiguity-fixed solutions could be obtained only $80 \%$ of the time. This percentage is relatively low compared to other NRTK services. Since Thailand is in a low-latitude region, atmospheric bias is especially problematic. This is due to the fact that ionospheric activity is much higher in a low-latitude region than in a mid-latitude region [7]. Previous studies [8] and [9] have shown the variation of ionospheric activity in Thailand region and confirmed that ionospheric irregularities usually occur at night time. [8] found that the ionospheric height varies anomaly in the night time with the occurrence of the spread F, they seems to be related. [9] stated that the pre-midnight scintillation occurrence is inhibited by magnetic activity. Considering the high variation of ionospheric effect in this region, mitigating ionospheric bias through the use of $60-\mathrm{km}$ reference station spacing may not provide reliable and accurate positioning solutions. This paper aims to test the performance of NRTK in Thai region on the basis of reference station spacing by incorporating the use of all available Continuous GPS (CGPS) stations in the central part of Thailand. In the following sections, the GPS data and software used are briefly described. The data processing is explained, followed by a discussion of the test results. Finally, some concluding remarks are given.

\section{GPS Data and Software Used}

Since this research focuses on the performance assessment of NRTK in Thailand with different reference receiver spacing distances, all available GPS data have been considered to form different sizes of VRS triangles. The data came from several Thai organizations including the Department of Lands (DOL), the Department of Public Works and Town and Country Planning (DPT), the Royal Thai Survey Department (RTSD), the Thai Meteorological Department (TMD), S.D.M. Company Limited (SDM), and Chulalongkorn University (Fig. 1). All stations used dual-frequency geodetic-grade GPS receivers. For a reliable statistical analysis, common GPS observation periods for all CGPS stations between February $1^{\text {st }}$, 2010 and March 3rd, 2010 (31 days) were selected. The GPS data were sampled at a 30-second rate giving rise to a total of 89,280 epochs. Moreover, the TEC values generated from GPS data at KMIT (King Mongkut's Institute of Technology) station, Bangkok was used in this research. The KMIT station is a part of the SouthEast Asia Low-latitude IOnospheric Network (SEALION) project for the purpose of monitoring and forecasting equatorial ionospheric disturbances, especially plasma bubbles in the Southeast Asia region. 
One of the main factors affecting the performance of NRTK is the accuracy of reference stations' coordinates. In order to obtain accurate coordinates of the CGPS stations, the scientific Bernese software version 5.0 [10] was employed. Trimble Total Control (TTC) version 2.73, a commercial post-processing software, was used to compute the coordinate solutions for roving receivers.

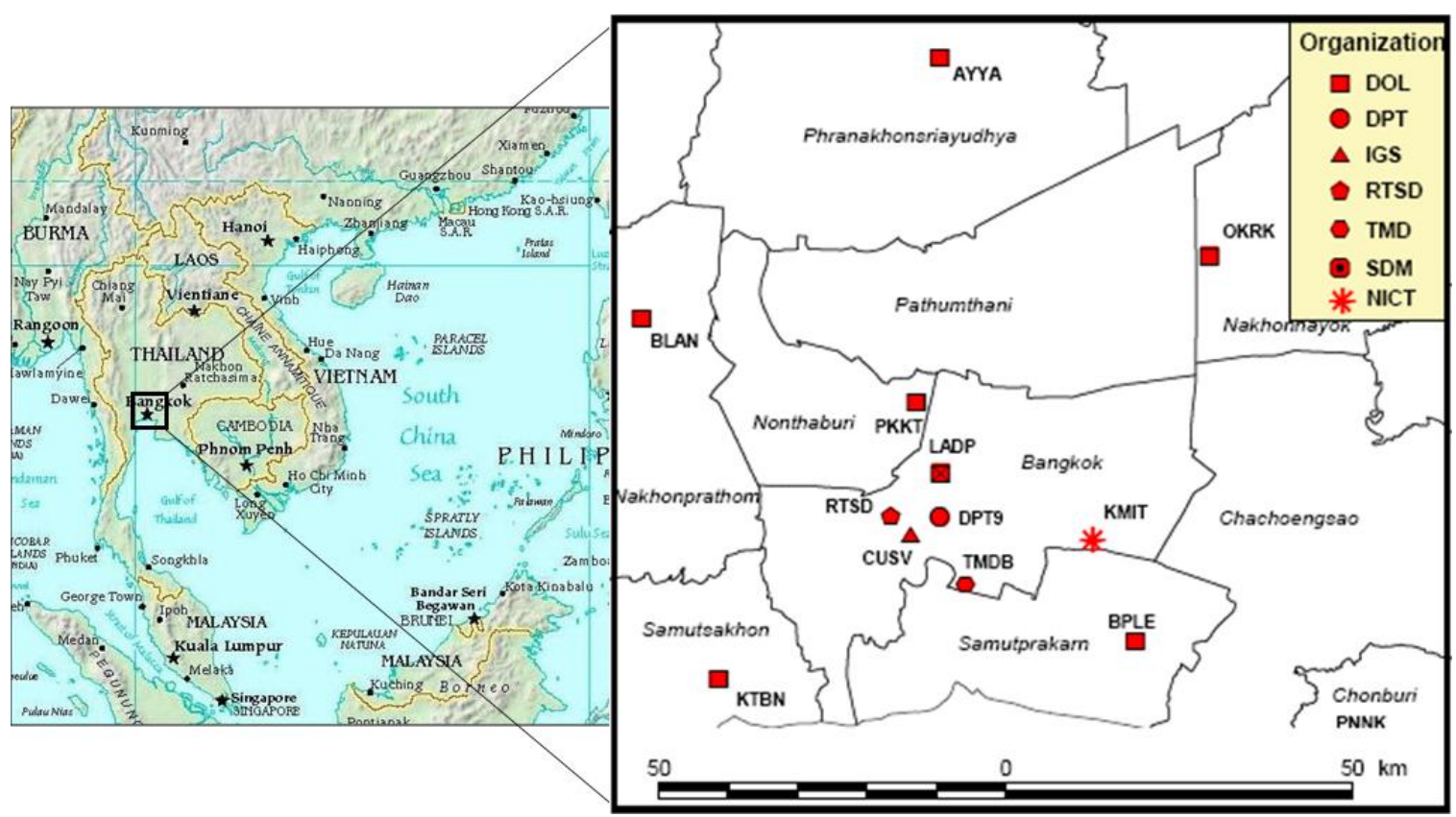

Fig. 1. The location of CGPS stations used in this research

\section{Data Processing}

All test data was processed in off-line mode. The processing consisted of three main steps as illustrated in Fig. 2. The first step was to establish the reference stations' coordinates while the second step dealt with the generation of the VRS observations for different reference receiver spacing distances nearby each roving station. The final step was the post-processing of NRTK solutions using VRS observations generated from the previous step. The details for each step are described in the following sub-sections.

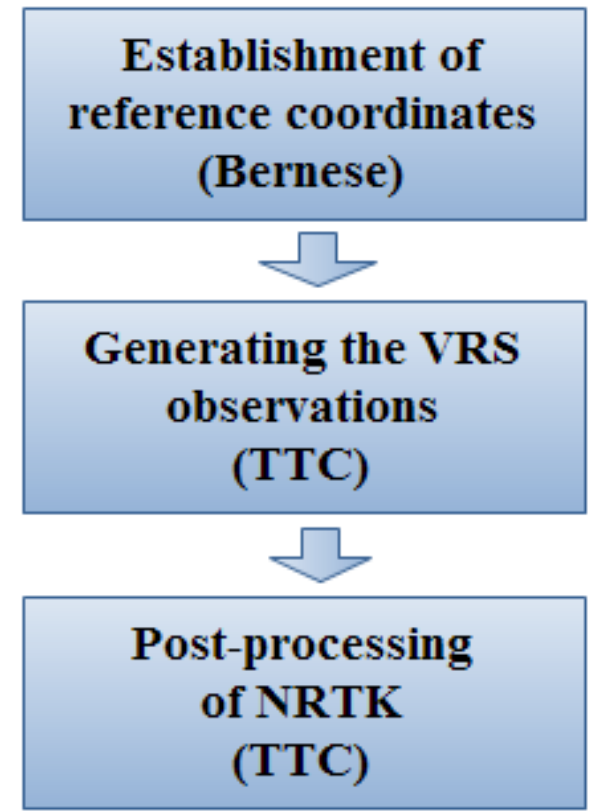

Fig. 2. The data processing steps 


\subsection{Establishment of coordinates for reference stations}

In order to obtain accurate reference coordinates of all stations, 7-day CGPS data (observed during February 1-7, 2010) were processed using the Bernese GPS Processing Software. A one-day solution was obtained for each station, using a standard processing baseline procedure. An International GNSS service (IGS) station located at Chulalongkorn University (CUSV) was selected as a fixed station and the IGS final orbits and satellite clock corrections were also introduced in the data processing step. The daily station coordinates for all GPS stations all agreed to within 6 millimeters. Consequently, on the basis of error propagation averaging, the weekly averaged solutions should be accurate to within a few millimeters. Therefore, the weekly averaged coordinates of an individual station can be used as reference coordinates for subsequent analysis.

\subsection{Generating VRS observations for different reference station spacing}

The TTC software is used to generate the VRS observations for different reference receiver spacing. The full network modeling of ionospheric, tropospheric and ephemeris errors, the so-called RTKNet mode is used to generate the VRS observations. The computation of ionospheric bias is based on the single layer model while the standard Saastamoinen model is used to mitigate the tropospheric bias. Since the study area is located in a flat plain area, an effect of tropospheric bias can also be neglected. In addition, the precise orbit is introduced in the data processing. Based on the available CGPS stations, four VRS triangles of $10-20 \mathrm{~km}, 30-50 \mathrm{~km}, 50-60 \mathrm{~km}$, and $60-80 \mathrm{~km}$ spacings were formed as shown in Fig. 3. Two static roving stations were selected as test points for each triangle. Hence, VRS observations can be generated from an accurate position of each roving station in each triangle.

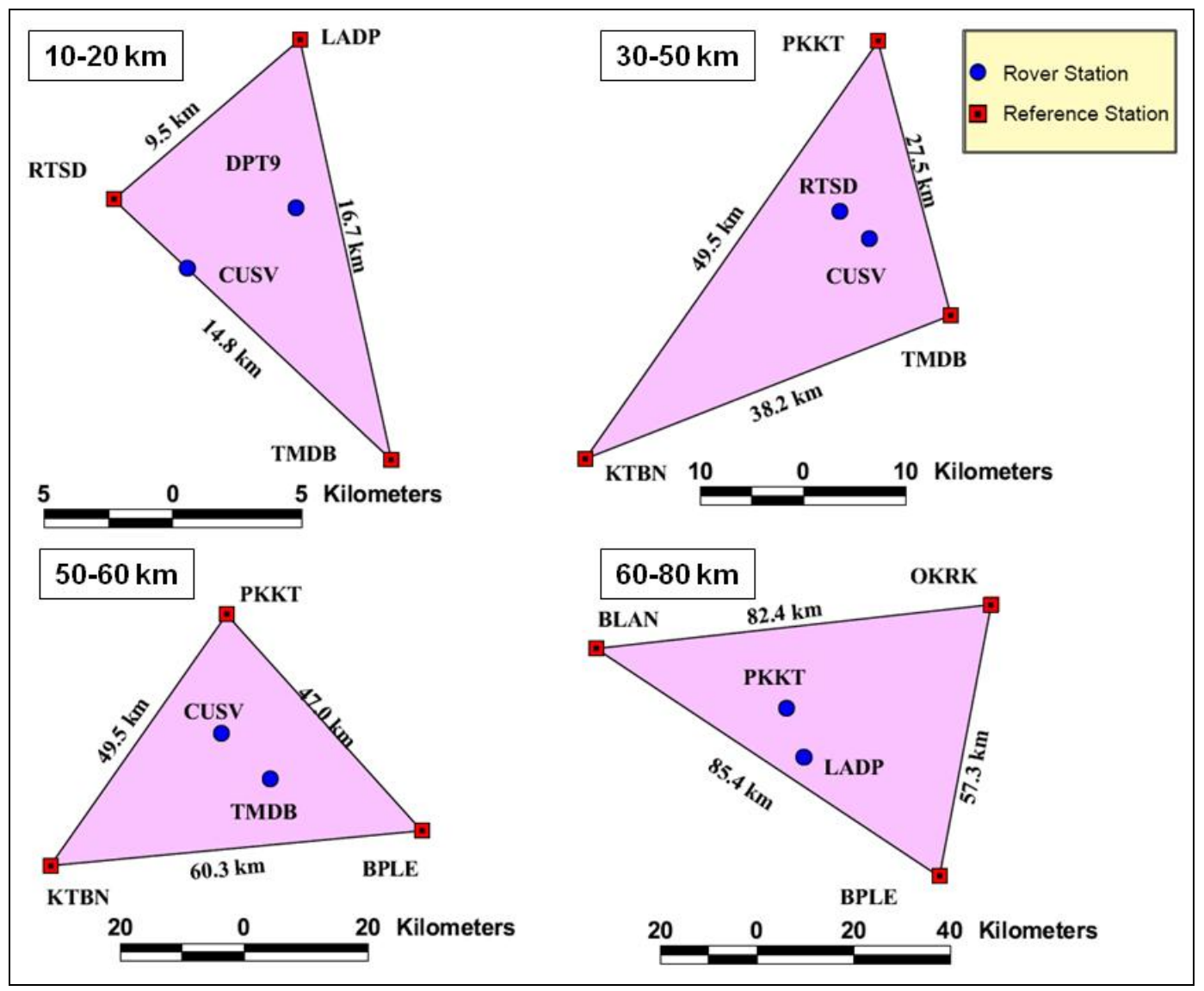

Fig. 3. Four different reference station spacing and roving receivers 


\subsection{Post-processing of NRTK}

To ensure consistency of final NRTK solutions, the TTC software was used to re-process the NRTK solutions in a post-processing mode. The standard RTK processing option was set to process between the generated VRS observations and the real observations collected at a roving receiver. The obtained NRTK solutions are described in the next section.

\section{Test Results}

After all data were processed, the final coordinates were compared with the reference coordinates. The performance of the NRTK technique can be characterized by three main indicators, namely, rate of ambiguity-fixing, rate of position jump, and Root Mean Square Error (RMSE). The rate of ambiguity-fixing is the percentage of ratio between the ambiguity-fixed solutions and all data $(89,280$ epochs) used in processing, while the rate of the position jump is the percentage of ratio between ambiguity-fixed solutions that fell outside a 5 -cm error circle. In this investigation, the rate of position jump is calculated separately for horizontal and vertical components. Similarly, both the horizontal and vertical RMSE values are computed to estimate the accuracy of ambiguity-fixed solutions. It should be noted that all indicators are the averaged values of the solutions obtained from two roving stations in each VRS triangle. These indicators are shown in Table 1. Further visual comparisons are plotted in Figs. 4, 5 and 6.

Table 1. Summary of the performance of NRTK for each reference station spacing.

\begin{tabular}{ccccccc}
\hline $\begin{array}{c}\text { Reference } \\
\text { Receiver }\end{array}$ & $\begin{array}{c}\text { Amb.-fixing rate } \\
\mathbf{( \% )}\end{array}$ & \multicolumn{2}{c}{$\begin{array}{c}\text { Rate of position jump } \\
(\mathbf{\%})\end{array}$} & \multicolumn{2}{c}{$\begin{array}{c}\text { RMSE } \\
\text { (m) }\end{array}$} \\
\cline { 3 - 4 } \cline { 6 - 7 } & & Hor. & Vert. & & Hor. & Vert. \\
\hline $10-20 \mathrm{~km}$ & 89 & 0 & 0.4 & & 0.011 & 0.023 \\
$30-50 \mathrm{~km}$ & 62 & 0.1 & 2.0 & & 0.012 & 0.036 \\
$50-60 \mathrm{~km}$ & 32 & 0.1 & 3.2 & & 0.014 & 0.044 \\
$60-80 \mathrm{~km}$ & 27 & 1.3 & 14.2 & & 0.035 & 0.072 \\
\hline
\end{tabular}

\section{Discussion of Results}

Table 1 indicates that the performance of NRTK is highly dependent on the reference station spacing. Shorter reference station spacing yields better performance. Considering the rate of ambiguity-fixing, the use of reference station spacing over $30 \mathrm{~km}$ is not recommended as it cannot deliver continuous and reliable positioning results. Although the $10-20 \mathrm{~km}$ reference station spacing was used, the rate of ambiguity-fixing is still relatively low (less than 95\%). In addition, more than 300 position jumps were observed. These position jumps may be due to the wrongly fixed ambiguity. It is clearly seen from Figs. 4 and 5 that the degradation of ambiguity-fixing rate and the increment of positioning jumps are highly correlated with the reference station spacing. This may be due to the influence of an ionospeheric bias. Further investigations into the possible error sources that affected the performance of NRTK are needed.

All GPS stations used in this research are permanent stations with a good observing environment. There are no satellite obstructions above horizon, and therefore multipath effect can be neglected. Generally, VRS corrections can be separated into dispersive and non-dispersive components [11]. Dispersive component typically exhibits rapid changes with high variations due to the effect of free electrons in the ionosphere [12], [13] and [14]. On the other hand, non-dispersive component changes slowly and smoothly over time due to the characteristic behavior of the tropospheric and orbit biases [11]. In the case of $10-20 \mathrm{~km}$ reference station spacing, the orbit bias should not have an impact on the performance of NRTK. Furthermore, this research area is located in a flat area (maximum elevation difference is less than $10 \mathrm{~m}$ ) and hence the effect of tropospheric bias can also be neglected. Thus, the main error source that could degrade the performance of NRTK in this research is the ionospheric bias. To validate this assumption, ionospheric variation expressed in term of rate of change of Total Electron 
Content Unit (TEC) with respect to time, so-called 'ROTI', is presented for a comparison. ROTI is one of the parameters that can be used to explain the ionospheric irregularities. ROTI value can be calculated using Eq. (1) and Eq. (2) [15].

$$
\mathrm{ROT}=\frac{\mathrm{TEC}_{k}^{i}-\mathrm{TEC}_{k-1}^{i}}{t_{k}-t_{k-1}}
$$

where TEC is the total electron content value, $i$ is the visible satellite, and $k$ is the time of epoch.

$$
\text { ROTI }=\sigma_{\text {ROT }}
$$

where $\sigma_{\mathrm{ROT}}$ is the standard deviation of ROT for each 5 minute time interval.

Selected NRTK solutions at CUSV station obtained on March 1, 2010 are plotted against the ROTI values in Fig. 7. With reference to Fig. 7, it is obvious that only small numbers of ambiguity-fixed solutions could be obtained during the period of high variation of ROTI values (between 20:00 and 24:00 local time). Thus, it can be concluded that the ionospheric variation seriously affects the performance of NRTK in lowlatitude region like Thailand. However, the normal NRTK solutions can be obtained during the period of low variation of ROTI values (except between 20:00 and 24:00 local time).

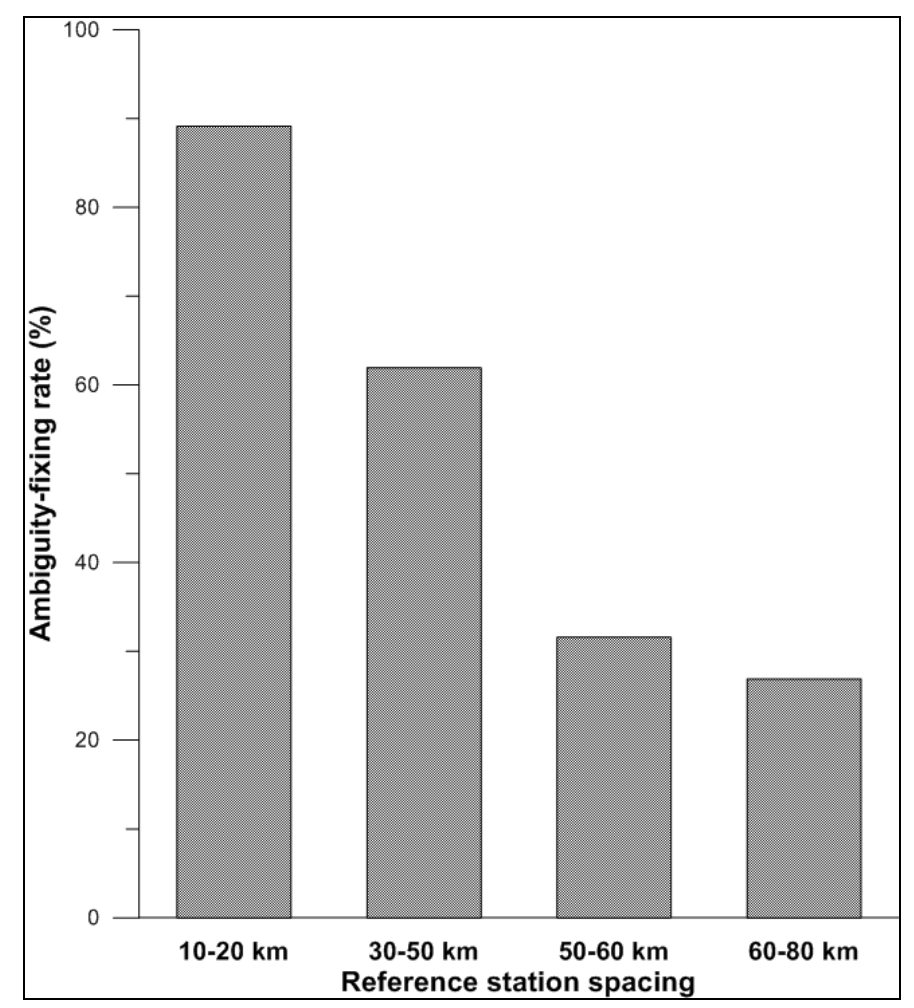

Fig. 4. Ambiguity-fixing rate for each reference station spacing. 


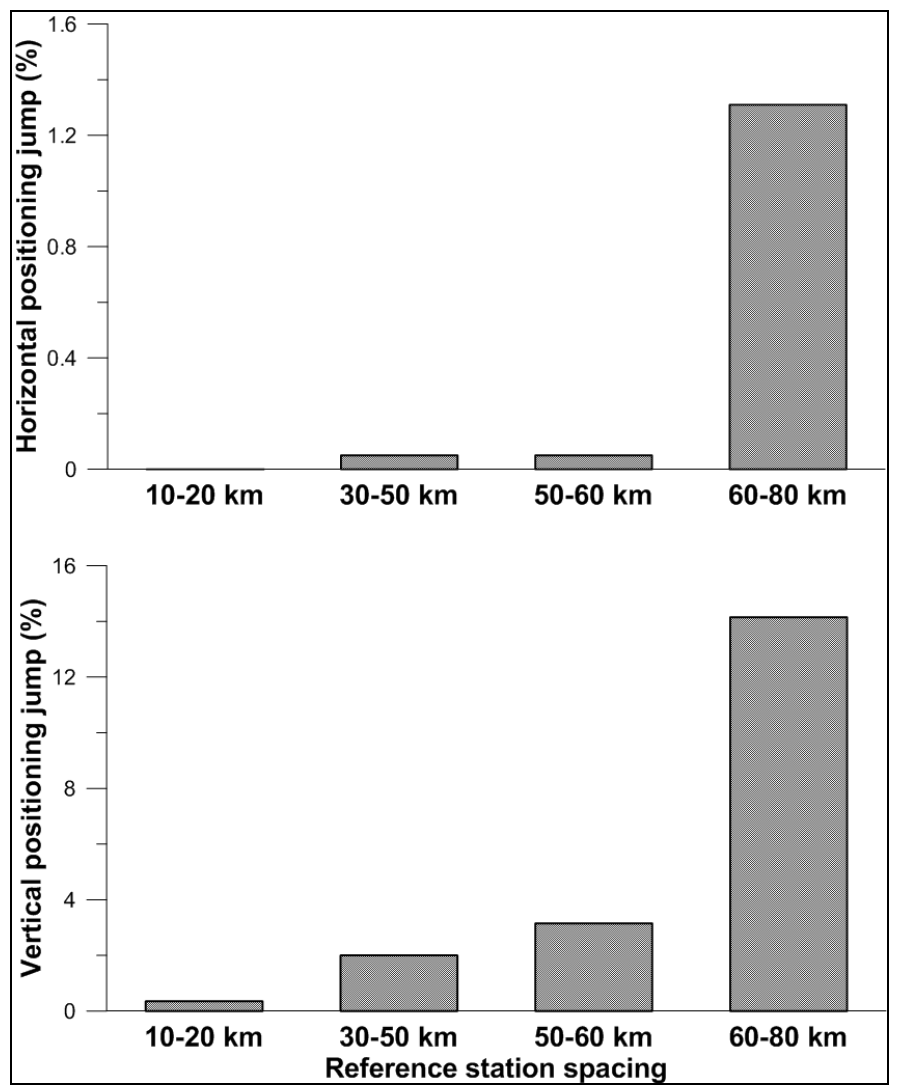

Fig. 5. The rate of position jump obtained from different reference station spacing (top: horizontal component; bottom: vertical component).

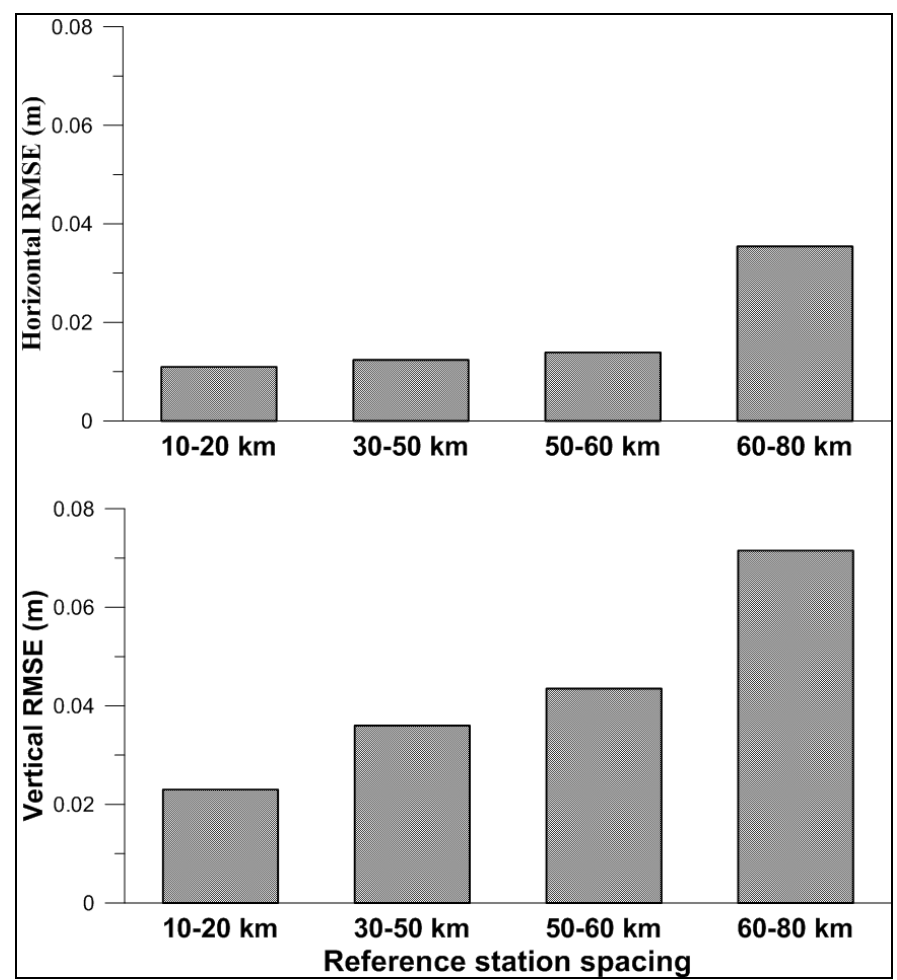

Fig. 6. RMSE values obtained from different reference station spacing (top: horizontal RMSE; bottom: vertical RMSE). 


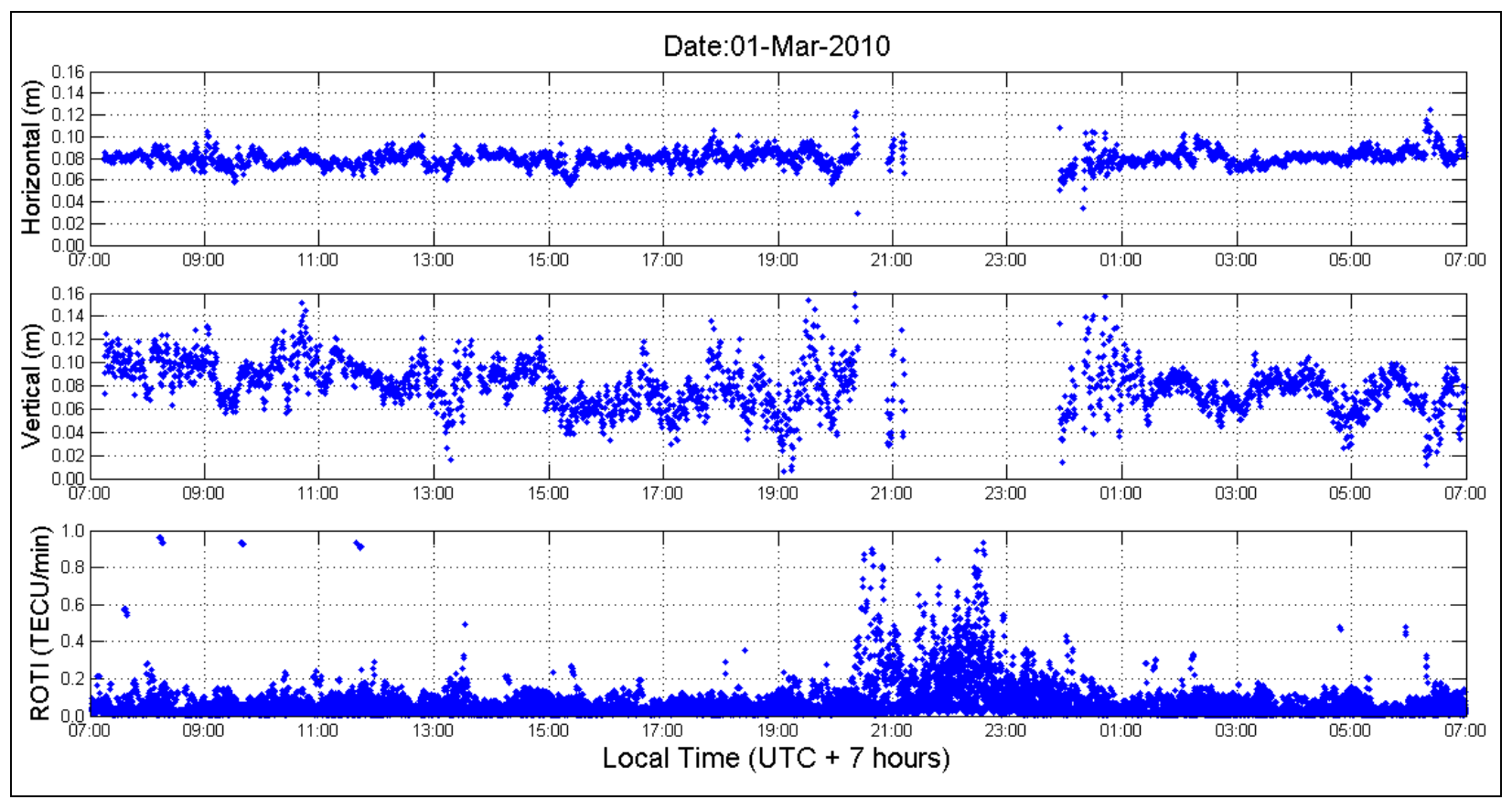

Fig. 7. The 10-20km NRTK solutions at CUSV station VS Ionospheric variation obtained on March 1 st, 2010 (top: horizontal accuracy; middle: vertical accuracy; bottom: ROTI value).

\section{Concluding Remarks}

In this paper, the performance of NRTK in Thailand has been tested using GPS observations collected on 31 consecutive days. Based on the available GPS observations, four different reference station spacings of $10-20 \mathrm{~km}, 30-50 \mathrm{~km}, 50-60 \mathrm{~km}$, and $60-80 \mathrm{~km}$ have been tested. The performance of the NRTK is degraded when the reference station spacing is increased. Although, 10-20 km reference station spacing gives the highest ambiguity-fixing rate and reliable position solutions, many position jumps even with the ambiguity-fixed solutions could still be observed. Our preliminary investigation suggests that the ionospheric error is the main error source which degrades the NRTK performance in Thailand since the rate of ambiguity-fixing is significantly decreased when the irregular ionospheric variation occurs. To ensure the high rate of ambiguity-fixing, it is recommended that the reference station spacing should be kept less than $30 \mathrm{~km}$. Finally, to achieve the high performance of NRTK in Thailand, a suitable method for interpolating the ionospheric error under a high ionospheric variation period should be investigated.

\section{Acknowledgements}

This research is supported by the National Research University Project of CHE and the Ratchadaphiseksomphot Endowment Fund (CC307A). The authors would like to thank the Department of Lands (DOL), Department of Public Works and Town and Country Planning (DPT), Royal Thai Survey Department (RTSD), Thai Meteorological Department (TMD) and S.D.M. Company Limited (SDM) and National Institute of Information and Communications Technology (NICT) of Japan for providing the CGPS data used in this study.

\section{References}

[1] C. Rizos and C. Satirapod, "Contribution of GNSS CORS infrastructure to the mission of modern geodesy and status of GNSS CORS in Thailand," Engineering Journal, vol. 15, no. 1, pp. 25-42, 2011.

[2] H. Jamil, A. Mohamed, and D. Chang, "The Malaysia real-time kinematic GNSS network (MyRTKnet) in 2010 and beyond," in FIG Congress 2010, Sydney, Australia, April 11-16, 2010, Paper no. 4742. 
[3] G. R. Hu, H. S. Khoo, P. C. Goh, and C. L. Law , "Development and assessment of GPS virtual reference stations for RTK positioning," Journal of Geodesy, vol. 77, no. 5, pp. 292-302, 2003.

[4] W. Chen, C. Hu, X. Ding, Y. Chen, and S. Kwok, "Critical issues on GPS RTK operation using Hong Kong GPS Active Network,” Journal of Geospatial Engineering, vol. 4, no. 1, pp. 31-40, 2010.

[5] K. W. Chiang, W. C. Peng, Y. H. Yeh, and K. H. Chen, "Study of alternative GPS network meteorological sensors in Taiwan: Case studies of the plum rains and Typhoon Sinlaku," Sensors, vol. 9, no. 6, pp. 5001-5021, 2009.

[6] T. Charoenkalunyuta and C. Satirapod, "Accuracy assessment of real-time kinematic GPS surveying using the first Virtual Reference Station (VRS) network in Thailand: Initial test results," Kasetsart Engineering Journal (in Thai), vol. 23, no. 70, pp.45-56, 2010.

[7] T. Musa, "Residual analysis of atmospheric delay in low latitude regions using network-based GPS positioning," Ph.D. Thesis, School of Surveying \& Spatial Information Systems, the University of New South Wales, Australia, 2007.

[8] R. Attaviriyasuwon, T. Boonchuk, N. Leelaruji, and N. Hemmakorn, "Observation of ionospheric height changes at Chumphon near the magnetic equator," in the 5th Int. Conf. on Information Communications and Signal Processing (ICICS 2005), Bangkok, Thailand, Dec 6-9, 2005, pp. 1169-1172.

[9] A. Gwal, A. Feliziani, S. Dubey, R. Wahi, and A. Gwal, "Amplitude and phase scintillation study at Chiang Rai, Thailand," Advances in Space Research, vol. 38, pp. 2361-2365, 2006.

[10] R. Dach, U. Hugentobler, P. Fridez, and M. Meindl, "Bernese GPS software Version 5.0," Astronomical Institute, University of Bern, Switzerland, 2007.

[11] S. Lim, C. Rizos, and T. Musa, "Application of running average function to non-dispersive errors of network-based real-time kinematic positioning," Journal of Global Positioning Systems, vol. 7, no. 2, pp. 148-155, 2008.

[12] P. M. Hernandes, J. M. Juan, and O. L. Colombo, "Precise ionospheric determination and its application to real-time GPS ambiguity resolution," in the 12th Int. Tech. Meeting of the Satellite Division of the ION, Nashville, Tennessee, Sept. 14-17, 1999, pp.1409-1417.

[13] D. Odijk, "Fast precise GPS positioning in the presence of ionospheric delays," Ph.D. Thesis, Delft University of Technology, Delft, the Netherlands, 2002.

[14] Y. Memarzadeh, "Ionospheric modeling for precise GNSS applications," Ph.D. Thesis, Delft institute of Earth Observation and Space systems (DEOS), Delft University of Technology, the Netherlands, 2009.

[15] X. Pi, A. J. Mannucci, U. J. Lindqwister, and C. M. Ho, "Monitoring of global ionospheric irregularities using the worldwide GPS network," Geophys. Res. Lett., vol. 24, no. 18, pp. 2283-2286, 1997, doi:10.1029/97GL02273. 
